\title{
Randomised controlled trial and economic evaluation of a targeted cancer awareness intervention for adults living in deprived areas of the UK
}

\author{
Yvonne Moriarty $\mathbb{D}^{1 凶}$, Mandy Lau ${ }^{1}$, Bernadette Sewell $\mathbb{D}^{2}$, Rob Trubey ${ }^{1}$, Harriet Quinn-Scoggins ${ }^{3}$, Sioned Owen ${ }^{4}$, Louise Padgett ${ }^{5}$, \\ Vasiliki Kolovou ${ }^{6}$, Julie Hepburn ${ }^{7}$, Peter Buckle ${ }^{8}$, Rebecca Playle ${ }^{1}$, Julia Townson ${ }^{1}$, Michael Robling ${ }^{1}$, Stephanie Gilbert ${ }^{1}$, \\ Polyxeni Dimitropoulou', Adrian Edwards ${ }^{3}$, Caroline Mitchell ${ }^{9}$, Maura Matthews ${ }^{4}$, Stephanie Smits ${ }^{3}$, Fiona Wood ${ }^{3}$, Richard D. Neal $^{10}$, \\ Kate Brain ${ }^{3}$ and ABACus study team*
}

(c) The Author(s) 2021

\begin{abstract}
BACKGROUND: Cancer outcomes are poor in socioeconomically deprived communities, with low symptom awareness contributing to prolonged help-seeking and advanced disease. Targeted cancer awareness interventions require evaluation.

METHODS: This is a randomised controlled trial involving adults aged $40+$ years recruited in community and healthcare settings in deprived areas of South Yorkshire and South-East Wales. Intervention: personalised behavioural advice facilitated by a trained lay advisor. Control: usual care. Follow-up at two weeks and six months post-randomisation. Primary outcome: total cancer symptom recognition score two weeks post-randomisation.

RESULTS: Two hundred and thirty-four participants were randomised. The difference in total symptom recognition at two weeks [adjusted mean difference (AMD) $0.6,95 \% \mathrm{Cl}:-0.03,1.17, p=0.06$ ] was not statistically significant. Intervention participants reported increased symptom recognition (AMD 0.8, 95\% Cl: $0.18,1.37, p=0.01$ ) and earlier intended presentation (AMD -2.0, 95\% $\mathrm{Cl}:-3.02,-0.91, p<0.001)$ at six months. "Lesser known" symptom recognition was higher in the intervention arm ( 2 weeks AMD $0.5,95 \% \mathrm{Cl}: 0.03,0.97$ and six months AMD 0.7, 95\% Cl: 0.16, 1.17). Implementation cost per participant was $£ 91.34$, with no significant between-group differences in healthcare resource use post-intervention.

CONCLUSIONS: Improved symptom recognition and earlier anticipated presentation occurred at longer-term follow-up. The ABACus Health Check is a viable low-cost intervention to increase cancer awareness in socioeconomically deprived communities. CLINICAL TRIAL REGISTRATION: ISRCTN16872545.
\end{abstract}

British Journal of Cancer (2021) 125:1100-1110; https://doi.org/10.1038/s41416-021-01524-5

\section{BACKGROUND}

Inequalities in cancer survival exist in the United Kingdom [1, 2]. The deprivation gap in cancer outcomes partly reflects socioeconomic differences in stage at diagnosis [3], with prolonged time to symptom presentation contributing to later stage diagnosis in lower socioeconomic groups [4, 5]. Cancer risk behaviours including smoking, alcohol and poor diet also contribute to higher cancer incidence and mortality in deprived communities [6]. Since the inception of the UK National Awareness and Early Diagnosis Initiative [7] and International Cancer Benchmarking Partnership [8], efforts have been focussed on understanding the root causes of international variation in cancer outcomes, including later symptom presentation and later stage diagnosis.
Early symptoms of common cancers can be difficult to recognise, and low awareness of potential cancer symptoms has been linked to longer time to help-seeking $[9,10]$. Previous studies have highlighted key behavioural influences on cancer symptom presentation, including perceived practical and emotional barriers [11], worry about wasting the doctor's time [12] and fearful and fatalistic beliefs about cancer [13, 14], especially among adults living in deprived communities [15-17]. While evidence suggests that interventions delivered via mass media campaigns can improve cancer outcomes [18-20], they may not reach people from lower socioeconomic groups [21].

Innovative approaches are therefore needed to expedite cancer diagnosis and improve outcomes among people from lower socioeconomic groups who are disproportionately affected by

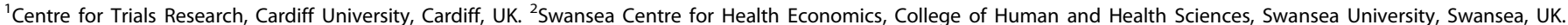

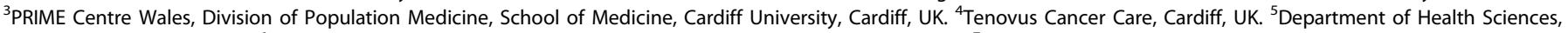

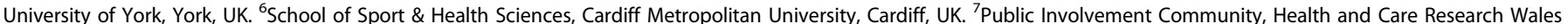

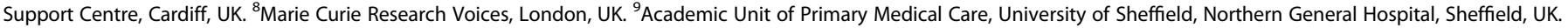
${ }^{10}$ Leeds Institute of Health Sciences, University of Leeds, Leeds, UK. ${ }^{11}$ A list of authors and their affiliations appears at the end of the paper. ${ }^{凶}$ email: MoriartyY@cardiff.ac.uk 
cancer. Cancer awareness interventions that are targeted at social and community networks have the potential to engage people living in deprived areas by signalling that timely help-seeking for suspected cancer symptoms is welcomed and legitimised [22]. Building on personal connections and trust using the trained peer supporter model may be a powerful way of spreading positive cancer awareness messages through the community. This is an established idea, especially in areas of deprivation where longterm health may not be a priority due to low resources [23]. Evidence suggests that community-based behavioural interventions facilitated by trained and trusted peer supporters are important for engaging underserved populations in cancer awareness and normalising earlier help-seeking [24, 25].

We developed the Awareness and Beliefs About Cancer (ABACus) Health Check, a targeted and tailored intervention designed to raise awareness of common cancers and encourage timely symptom help-seeking among adults living in socioeconomically deprived communities [26]. Early evidence demonstrated successful engagement and potential for intervention scalability, reach and adoption in non-medical community settings in areas of deprivation [27]. We trialled the effectiveness of the intervention in increasing cancer awareness and help-seeking behaviour among adults recruited in socioeconomically deprived areas of Yorkshire and Wales.

\section{METHODS}

Trial methods are reported in detail in the published protocol [28].

\section{Study design}

This was an unblinded, individually randomised controlled trial of a facilitated Health Check intervention hosted online and delivered by three trained lay advisors in areas of high deprivation in South and West Yorkshire and South-East Wales.

\section{Participants}

Participant inclusion criteria were: adults aged $\geq 40$ years recruited from venues in socioeconomically deprived areas (i.e. lowest quintile measured using the Index of Multiple Deprivation (IMD) [29]/Welsh Index of Multiple Deprivation (WIMD) [30]) of South and West Yorkshire (Sheffield, Barnsley, Rotherham, Wakefield, Doncaster) or South-East Wales (Merthyr Tydfil and Newport). Exclusion criteria were: non-English speaking, unable to give written informed consent, or participation in the Phase 2 study [28].

\section{Recruitment and settings}

Full details of recruitment and settings for recruitment are published [27]. Briefly, local delivery organisations situated in eligible community and healthcare settings (i.e. located in an area of socioeconomic deprivation) were approached by the lay advisors, who sought permission to access the organisation's facilities for recruitment purposes and delivering the Health Check intervention. They acted as recruitment venues and enabled access to members of the public and provided a suitable private space for the intervention delivery. Community settings included venues hosting local community events and groups, for example, job shops, libraries and sheltered housing. Healthcare settings included general practitioner (GP) surgeries and pharmacies.

\section{Sample size}

We aimed to recruit 246 participants providing $90 \%$ power to detect an effect size of 0.5 in the primary outcome (using a two-sided $t$ test, at the $5 \%$ significance level and assuming 30\% attrition) to demonstrate an average increased recognition of one cancer symptom $(S D=2.2)$.

\section{Randomisation}

Immediately following baseline data collection, participants were randomised to the intervention or control. Participants were randomised using permuted blocks of size 2, 4 and 6 on a 1:1 ratio and informed immediately of the outcome by the lay advisor.

\section{Intervention}

The ABACus Health Check intervention was specifically developed to improve awareness of a range of cancers and reduce time to symptom presentation among adults living in areas of socioeconomic deprivation in the UK $[22,26]$. The intervention was co-produced with local stakeholders and grounded in behaviour change theory, with social support and enablement provided by a credible lay advisor identified as key intervention functions [26]. In keeping with the principles of co-production, the intervention focussed on cancer symptom awareness, while acknowledging stakeholders' views on the importance of addressing underlying cancer risk factors. It comprises an interactive touchscreen questionnaire about common cancer symptoms, cancer screening and risk factors (smoking, alcohol, diet and activity) with personalised results, support and advice delivered by a trained lay advisor drawing on seven behaviour change techniques (i.e. Information about health consequences; Prompts/ cues; Credible source; Restructuring the social environment; Social support; Goal setting (behaviour) and Action planning) tailored to the individual's results [22]. Three lay advisors were specifically employed to recruit participants and deliver the Health Check. They all had either undergraduate or Master's level education and had a health promotion background. Further description of the intervention reported according to the TIDieR checklist [31] can be found in Supplementary Table 1.

\section{Control}

Participants randomised to the control group were provided with the usual available care and support accessible through their GP or community organisations where applicable.

\section{Data collection}

Data were collected at baseline, two weeks and six months following randomisation. At baseline, data were collected face-to-face using an iPad and entered directly into a bespoke study database. Subsequent data collection was carried out over the telephone or by postal survey according to the participant's preference. Participants were offered a total of $£ 15$ in high street shopping vouchers as an incentive to take part, one supplied at baseline $(£ 10)$ and one after completion of the six months follow-up questionnaire $(£ 5)$.

\section{Process evaluation}

The method and results of the process evaluation are reported separately (HQ-S, YM, SG, SS, VS, JH, et al. unpublished) and included participant interviews at two to six weeks post-baseline, audio recordings and observations of the Health Check delivery, interviews with the lay advisors prior to and post participant recruitment and recruitment day logs written by the lay advisors.

\section{Primary outcome}

The primary outcome was total cancer symptom recognition score measured two weeks after randomisation, using an adapted version of the Awareness and Beliefs about Cancer measure (ABC) [32]. See Supplementary Table 2 for further details on measures used.

\section{Secondary outcomes}

Secondary outcomes included anticipated symptom presentation for selected symptoms (unusual lump, rectal bleeding, persistent cough, unexplained weight loss); barriers to symptom presentation; beliefs about cancer; state anxiety (details of these in Supplementary Table 2); Health Check implementation costs; cost of subsequent healthcare resource use; demographic and health-related variables.

Health Check intervention implementation costs. Intervention costs considered in the health economic analysis included the cost of training the lay advisors, costs related to intervention face-to-face delivery and equipment to deliver the Health Check, which was assumed to be replaced after a mean lifespan of 3 years. Resource use and costs associated with intervention implementation were taken from recruitment day logs and notes, receipts and through discussions with the study team. Training costs were calculated based on data obtained from study training logs, costed using published unit costs [33]. ABACus Health Check development costs were not included in these costs as the intervention was fully developed [26] at the time of the study. 
Cost of subsequent healthcare resource use. Subsequent healthcare resource use associated with symptoms that could be due to cancer at baseline and six months including primary care consultations, accident and emergency department visits, outpatient appointments, inpatient stays, imaging and investigations and advice related to potential cancer symptoms was established using a Client Service Receipt Inventory (CSRI) [34], adapted for healthcare resource use collection in people living in socioeconomically deprived. Each CSRI questionnaire asked for potential cancer symptom-related healthcare resource use in the past six months. Costs were assigned as 2018 Pound Sterling using published unit costs $[33,35]$. Cancer treatment related to confirmed cancer was collected but not included in the total cost.

Demographic and health-related variables. Demographic background variables included age, gender, ethnicity, current relationship status, highest level of education, employment and home ownership. IMD [29] and WIMD [30] scores were calculated from postcodes. Experience of cancer (self, family and friends) and self-rated health were assessed.

\section{Statistical analyses}

Data were analysed using intention-to-treat principles (i.e. participants remained in the groups to which they were assigned irrespective of intervention received) using complete cases. The primary analyses applied a linear model to total cancer symptom recognition score at two weeks follow-up. Mixed-effects two-level partial cluster regression models were used to adjust for lay advisors as a stratification variable and to allow for clustering by advisor. The distributional assumptions of the linear model were checked and transformed where appropriate. Bootstrapping was used to generate regression coefficients and confidence intervals (Cls) if the distributions remained non-normal. The mean (SD) score for the intervention and control groups at baseline and follow-up were tabulated. The primary outcome effect was presented adjusted for baseline score, with $95 \%$ Cl. Pre-specified exploratory subgroup analyses were run for age, gender, recruitment setting and education. Secondary outcomes were analysed similarly. The consistency of conclusions drawn from the primary analysis was investigated by conducting sensitivity analyses for: (i) missing responses (i.e. not missing completely at random); (ii) data collected outside the designated two weeks follow-up window. Psychometric testing of baseline data was conducted to assess the internal validity and reliability of the adapted ABC measures, with Cronbach's alpha coefficient to assess the internal consistency of the scales and appropriate regressions applied to subscales generated from factor analysis (Supplementary Table 3).
For all analyses, two-sided $95 \% \mathrm{Cls}$ and $p$ values were calculated. $p$ Values $<0.05$ were considered statistically significant. Statistical analyses were conducted using IBM SPSS version 25 and STATA version 15.

\section{Health economic analyses}

The cost differences between intervention and control groups in the six months post-randomisation, based on all available cases, were calculated using SPSS version 26. Independent samples $t$ tests, adjusted using Bonferroni-Holm sequential corrections [36], were used for comparison of control and intervention group data and paired $t$ tests for within-group differences between baseline and six months follow-up, with a $5 \%$ significance level. A within-trial cost-effectiveness analysis calculated the incremental cost per point improvement in cancer symptom awareness score at the six months follow-up point in the intention-to-treat population. Trial results extrapolated to a longer time horizon and published evidence were used to estimate the incremental cost per quality-adjusted life-year (QALY) gained based on a combined decision tree and Markov model constructed using Microsoft Excel and Visual Basics for Applications over a five year time horizon. This analysis assumed that encouraging earlier presentation with cancer symptoms would result in potential effects on health outcomes and healthcare costs based on a simulated cohort of 100,000 people living in socioeconomically deprived areas of the UK. The analysis was undertaken from an NHS and personal social services perspective with costs and outcomes discounted at an annual rate of $3.5 \%$. Deterministic and probabilistic sensitivity analyses were undertaken to test the robustness of the results.

\section{RESULTS}

Overall, 448 members of the public were approached to take part during the study period between December 2017 and January 2019, of whom 29 were ineligible, 42 declined due to lack of interest and 141 declined for other reasons (e.g. insufficient time) (Supplementary Table 4). Following consent, two participants were withdrawn due to incomplete baseline questionnaires. A total of 234 participants (82 from South East Wales (35\%) and 152 from South and West Yorkshire $(65 \%))$ were randomised to the intervention $(n=117,50 \%)$ or control ( $n=117,50 \%)$ (Fig. 1). Despite a lower than planned sample recruited $(n=249)$, the study attrition rate of $9.5 \%$ [27] was much lower than anticipated (30\%) [28] and therefore the trial was adequately powered.

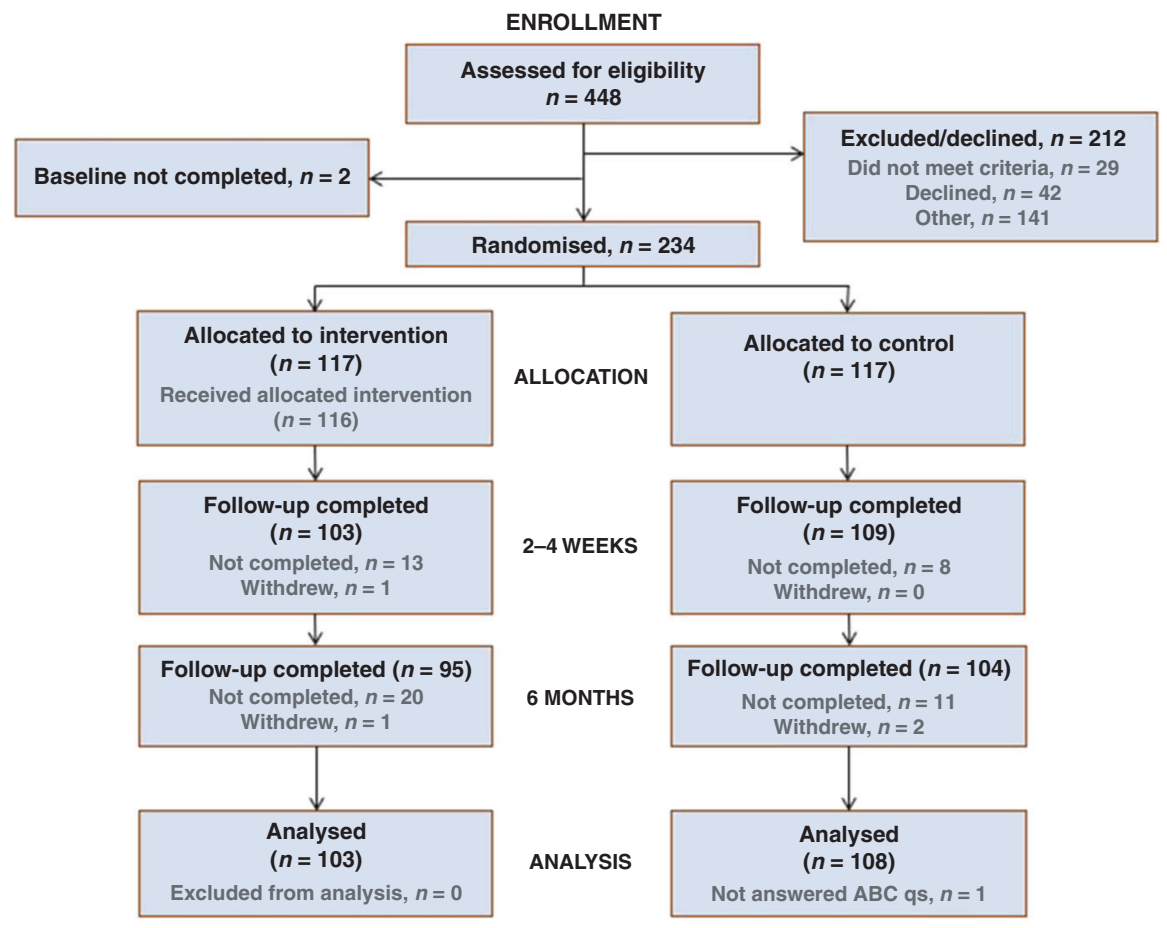

Fig. 1 Consort flow diagram. 
Table 1. Sociodemographic characteristics of participants at baseline $(N=234)$.

\begin{tabular}{|c|c|c|c|c|c|c|}
\hline \multirow[t]{2}{*}{ Characteristics } & \multicolumn{2}{|c|}{$\begin{array}{l}\text { Control } \\
(n=117)\end{array}$} & \multicolumn{2}{|c|}{$\begin{array}{l}\text { Health Check } \\
(n=117)\end{array}$} & \multicolumn{2}{|c|}{$\begin{array}{l}\text { Total } \\
(n=234)\end{array}$} \\
\hline & $n$ & $\%$ & $n$ & $\%$ & $n$ & $\%$ \\
\hline Age (years), mean (SD) & 61.9 & $(11.47)$ & 60.7 & $(11.85)$ & 61.3 & (11.65) \\
\hline Male & 50 & 42.7 & 36 & 30.8 & 86 & 36.8 \\
\hline Female & 67 & 57.3 & 81 & 69.2 & 148 & 63.2 \\
\hline Finished school at or before age of 15 years & 36 & 30.8 & 39 & 33.3 & 75 & 32.1 \\
\hline Completed GCSEs, O-Levels or equivalent & 21 & 17.9 & 26 & 22.2 & 47 & 20.1 \\
\hline Completed A levels or equivalent & 5 & 4.3 & 9 & 7.7 & 14 & 6.0 \\
\hline Completed further education but not degree & 22 & 18.8 & 14 & 12.0 & 36 & 15.4 \\
\hline Completed a bachelor's degree/masters/PhD & 8 & 6.8 & 10 & 8.5 & 18 & 7.7 \\
\hline Retired & 58 & 49.6 & 50 & 42.7 & 108 & 46.2 \\
\hline Unemployed & 15 & 12.8 & 22 & 18.8 & 37 & 15.8 \\
\hline Self-employed & 3 & 2.6 & 3 & 2.6 & 6 & 2.6 \\
\hline Disabled or too ill to work & 13 & 11.1 & 19 & 16.2 & 32 & 13.7 \\
\hline Prefer not to say & 0 & 0.0 & 1 & 0.9 & 1 & 0.4 \\
\hline \multicolumn{7}{|l|}{ Home/living arrangement } \\
\hline Own outright & 48 & 41.0 & 34 & 29.1 & 82 & 35.0 \\
\hline Own mortgage & 8 & 6.8 & 12 & 10.3 & 20 & 8.5 \\
\hline Rent form local authority/housing association & 44 & 37.6 & 49 & 41.9 & 93 & 39.7 \\
\hline Rent privately & 14 & 12.0 & 17 & 14.5 & 31 & 13.2 \\
\hline Living with family or friends & 3 & 2.6 & 3 & 2.6 & 6 & 2.6 \\
\hline White and Black Caribbean & 0 & 0.0 & 1 & 0.9 & 1 & 0.4 \\
\hline White and Black African & 1 & 0.9 & 0 & 0.0 & 1 & 0.4 \\
\hline Pakistani & 1 & 0.9 & 0 & 0.0 & 1 & 0.4 \\
\hline Caribbean & 0 & 0.0 & 1 & 0.9 & 1 & 0.4 \\
\hline Other ethnic group & 0 & 0.0 & 1 & 0.9 & 1 & 0.4 \\
\hline \multicolumn{7}{|l|}{ Welsh Index of Multiple Deprivation $(n=82)$} \\
\hline $10 \%$ most deprived & 15 & 36.6 & 16 & 39.0 & 31 & 37.8 \\
\hline $10-20 \%$ most deprived & 9 & 22.0 & 9 & 22.0 & 18 & 22.0 \\
\hline $20-30 \%$ most deprived & 7 & 17.1 & 6 & 14.6 & 13 & 15.9 \\
\hline $30-40 \%$ most deprived & 6 & 14.6 & 3 & 7.3 & 9 & 11.0 \\
\hline $50 \%$ least deprived & 4 & 9.8 & 7 & 17.1 & 11 & 13.4 \\
\hline \multicolumn{7}{|l|}{ Index of Multiple Deprivation ( $n=152)$} \\
\hline $10 \%$ most deprived & 47 & 61.8 & 37 & 48.7 & 84 & 55.3 \\
\hline $20 \%$ most deprived & 9 & 11.8 & 12 & 15.8 & 21 & 13.8 \\
\hline $30 \%$ most deprived & 3 & 3.9 & 8 & 10.5 & 11 & 7.2 \\
\hline $40 \%$ most deprived & 4 & 5.3 & 8 & 10.5 & 12 & 7.9 \\
\hline $50 \%$ most deprived & 2 & 2.6 & 0 & 0.0 & 2 & 1.3 \\
\hline $50 \%$ least deprived & 3 & 3.9 & 6 & 7.9 & 9 & 5.9 \\
\hline $40 \%$ least deprived & 1 & 1.3 & 2 & 2.6 & 3 & 2.0 \\
\hline $30 \%$ least deprived & 6 & 7.9 & 1 & 1.3 & 7 & 4.6 \\
\hline $20 \%$ least deprived & 1 & 1.3 & 1 & 1.3 & 2 & 1.3 \\
\hline
\end{tabular}


Table 1 continued

\begin{tabular}{|c|c|c|c|c|c|c|}
\hline \multirow[t]{2}{*}{ Characteristics } & \multicolumn{2}{|c|}{$\begin{array}{l}\text { Control } \\
(n=117)\end{array}$} & \multicolumn{2}{|c|}{$\begin{array}{l}\text { Health Check } \\
(n=117)\end{array}$} & \multicolumn{2}{|c|}{$\begin{array}{l}\text { Total } \\
(n=234)\end{array}$} \\
\hline & $n$ & $\%$ & $n$ & $\%$ & $n$ & $\%$ \\
\hline $10 \%$ least deprived & 0 & 0.0 & 1 & 1.3 & 1 & 0.7 \\
\hline Yes & 27 & 23.1 & 21 & 18.3 & 48 & 20.7 \\
\hline No & 90 & 76.9 & 94 & 81.7 & 184 & 79.3 \\
\hline No & 95 & 81.9 & 101 & 87.1 & 196 & 84.5 \\
\hline \multicolumn{7}{|c|}{ Has a close family member had cancer? } \\
\hline Yes & 83 & 70.9 & 93 & 79.5 & 176 & 75.2 \\
\hline No & 34 & 29.1 & 24 & 20.5 & 58 & 24.8 \\
\hline \multicolumn{7}{|c|}{ Has another family member had cancer? } \\
\hline No & 49 & 42.2 & 50 & 43.5 & 99 & 42.9 \\
\hline \multicolumn{7}{|c|}{ Has another friend had cancer? } \\
\hline Yes & 80 & 69.0 & 72 & 62.6 & 152 & 65.8 \\
\hline No & 36 & 31.0 & 43 & 37.4 & 79 & 34.2 \\
\hline
\end{tabular}

Recruited participants had a mean age of 61.3 years $(S D=11.65)$. Most participants were white $(229 / 234,97.9 \%)$ and around two thirds were female $(148 / 234,63.2 \%)$. Around half of participants were retired $(108 / 234,46.2 \%)$ and had no formal qualifications or finished school at age $\leq 16$ years (129/234, 55.1\%). Around half of participants were living with a partner or spouse $(123 / 234,52.6 \%)$ and just over one-third were renting from a local authority or housing association (93/234, 39.7\%). Most participants were resident in the $20 \%$ most deprived areas (WIMD: 49/82, 59.8\%; IMD: 105/152, 69.1\%). Baseline characteristics for participants (experiences of cancer) were well balanced between trial groups (Table 1). Baseline data were comparable between groups with a mean baseline cancer symptom recognition score of 9.0/12 and $8.9 / 12$ in the control and Health Check groups, respectively (Supplementary Table 5). Retention was high at two weeks (212/ 234, 90.5\%) and six months follow-up (99/234, 85.0\%) and comparable between groups. No further sensitivity analyses were required (Supplementary Tables 6 and 7).

\section{Primary outcome}

Difference in cancer symptom recognition score at two weeks follow-up was not statistically significant between groups (adjusted mean difference (AMD): $0.6,95 \% \mathrm{Cl}:-0.03$ to $1.17, p$ $=0.06$ ) (Table 2). There was no evidence of an intervention effect in the pre-specified subgroup analyses and one ad hoc subgroup analysis (Supplementary Table 8). Primary outcome data collected outside the two weeks follow-up window were adjusted to include data collected outwith the two week window, with no change in difference (Supplementary Table 9).

\section{Secondary outcomes}

At six months follow-up, participants allocated to the Health Check had statistically significantly increased symptom recognition (AMD: $0.8,95 \% \mathrm{Cl}: 0.18$ to $1.37, p=0.01$ ) and reported shorter anticipated time to presentation (AMD: $-2.0,95 \% \mathrm{Cl}$ : -3.02 to $-0.91, p<0.001)$ compared to control. There were no statistically significant differences between groups at two weeks in anticipated symptom presentation (AMD: $-0.8,95 \% \mathrm{Cl}$ : -1.79 to 0.29 ), perceived barriers to presentation (AMD: $0.1,95 \% \mathrm{Cl}:-0.23$ to 0.41 ), beliefs about cancer (AMD: $-0.02,95 \% \mathrm{Cl}:-0.50$ to 0.45 ) and state anxiety (AMD: $0.03,95 \% \mathrm{Cl}:-0.11$ to 0.18 ). There was no evidence of difference between groups in perceived barriers (AMD: $0.3,95 \% \mathrm{Cl}:-0.36$ to 0.91 ), beliefs about cancer (AMD: $-0.03,95 \% \mathrm{Cl}:-0.45$ to 0.38 ) and state anxiety (AMD: $0.81,95 \% \mathrm{Cl}$ : -0.10 to 1.72 ) at six months (Table 2 ).

A large ceiling effect was observed for recognition of "wellknown" cancer symptoms at baseline (Fig. 2). Health Check intervention participants had higher recognition of "lesser known" cancer symptoms at two weeks (AMD: $0.5,95 \% \mathrm{Cl}: 0.03$ to 0.97 ) and six months (AMD: $0.1,95 \% \mathrm{Cl}: 0.16$ to 1.17 ). No betweengroup difference was found for recognition of "well-known" cancer symptoms at two weeks (AMD: $0.1,95 \% \mathrm{Cl}$ : -0.16 to 0.27 ) and six months (AMD: $0.1,95 \% \mathrm{Cl}:-0.09$ to 0.28 ) (Table 3).

\section{Health economics}

During the study, 116 Health Checks were undertaken by three lay advisors at an intervention implementation cost of $£ 91.34$ per participant. This consisted of $£ 12.51$ lay advisor training cost, $£ 21.05$ staff cost for Health Check delivery and $£ 57.78$ equipment cost (including online hosting and technical support of the Health Check questionnaire, iPads, laptops and mobile phones and mobile printing equipment) per participant. Total healthcare costs related to symptoms that could be due to cancer (based on available cases) in the six months follow-up period included the cost of all primary and secondary care as well as diagnostic investigations and symptom-related advice (Table 4). Participants in the Health Check intervention group had $£ 11.64$ (95\% Cl: $£ 198.77$ to $£ 175.50$ ) lower total healthcare costs compared to the control group in the six months after baseline. The difference was not statistically significant $(p=0.90)$. After adding the Health Check implementation costs for all participants in the Health Check intervention group who had available healthcare resource use data, participants in the intervention group accrued a mean cost of $£ 225.82(S D=£ 641.41)$ at six months. The difference of $£ 79.70$ (95\% Cl: $-£ 107.43$ to $£ 266.84$ ) compared to the control group was not statistically significant $(p=0.40)$. 


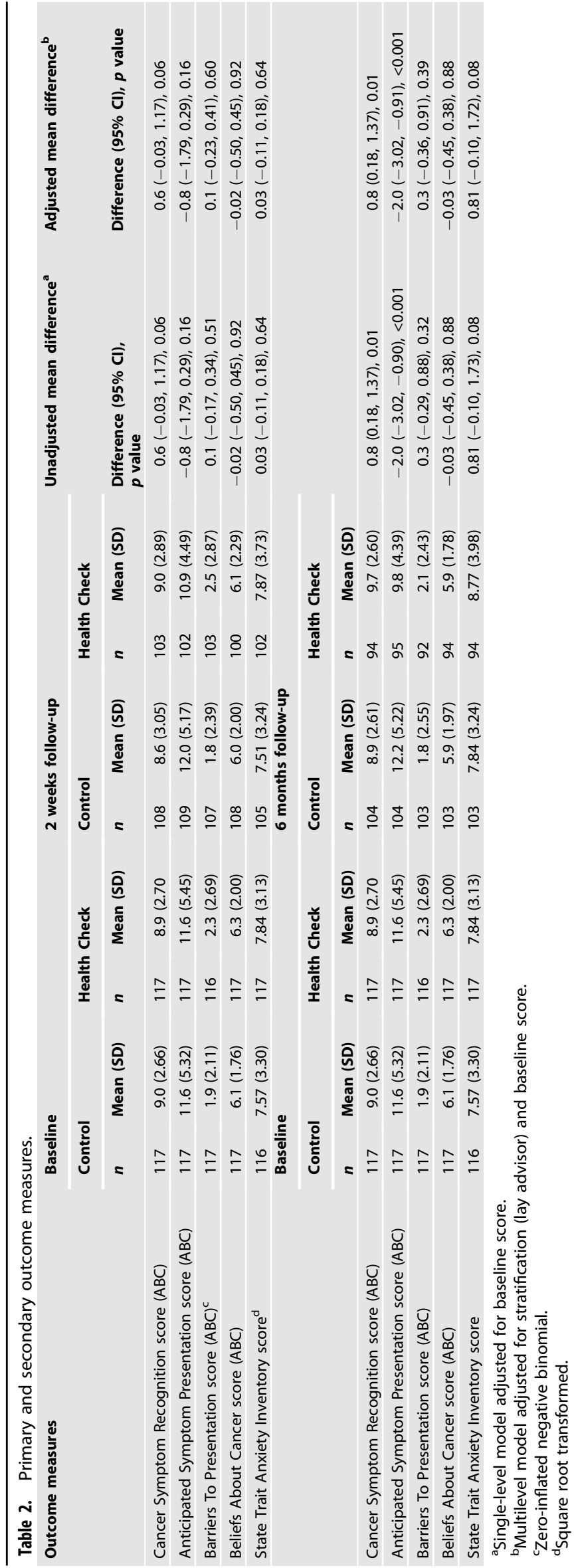

Based on the differences in costs and outcomes in the intention-to-treat population, the Incremental Cost-Effectiveness Ratio (ICER) was calculated to be $£ 108.85$ per point improvement in cancer symptom recognition score, with ICERs ranging from $£ 31.51$ to $£ 205.97$ in the sensitivity analysis. When the incremental cost of Health Check implementation, changes in healthcare resource use and downstream changes in healthcare cost as well as survival due to potentially earlier cancer detection are considered, the model-based cost-utility analysis estimated that the intervention is on average $£ 4.08$ less costly and produces 0.005 more QALYs than the control and thus is dominating. No change to the base case conclusion was found in the one-way sensitivity analyses conducted. The Health Check was dominating or cost-effective in all analyses and produced marginal cost savings of $£ 3.58$ per person when no impact on early diagnosis probability was assumed. In 100,000 probabilistic sensitivity analysis iterations, use of the Health Check was found to be less costly and more effective than the control on average. However, due to the small differences in cost and effect, results are distributed across all four sectors of the cost-effectiveness plane (Supplementary Fig. 1). Overall, the probability that the Health Check is cost-effective at willingness-to-pay thresholds of $£ 20,000$ and $£ 30,000$ per QALY gained is 88.6 and $95.5 \%$, respectively (Supplementary Fig. 2).

\section{DISCUSSION}

\section{Summary of key findings}

We conducted a randomised controlled trial to evaluate the effectiveness of a novel targeted and tailored behaviour change intervention designed to improve cancer awareness and address barriers to symptom presentation among adults living in socioeconomically deprived communities of the UK. Differences in total symptom recognition were not observed at short-term follow-up, but there was evidence of longer-term knowledge retention and shorter intended presentation among participants who received the intervention. While baseline levels of symptom awareness were high, recognition of "lesser known" symptoms such as persistent fatigue and unexplained weight loss improved, and there was no evidence of increased anxiety due to taking part in the Health Check. Effects on perceived barriers to symptom presentation and beliefs about cancer were not observed. The Health Check intervention was delivered at low cost and did not generate additional healthcare resource use in the six months post intervention.

\section{Discussion of findings within context of the literature}

The design and evaluation of cancer awareness interventions is challenging for several reasons. Intervention intensity and duration are often limited by financial constraints, and evaluation methods are typically restricted to observational designs with short follow-up (e.g. Ironmonger et al. [18], McCutchan et al. [20]). Furthermore, designing robust controlled trials of cancer awareness interventions is problematic due to the demands of selecting a suitable comparator and outcome measures, which may inadvertently compromise intervention design and dose. The Improving Rural Cancer Outcomes trial was unique in randomising whole communities in Western Australia to receive a symptom awareness campaign in intervention areas compared to a matched control area [37]. However, no significant intervention effects were observed, possibly reflecting the omission of TV broadcast media from the intervention due to concerns about cost and trial contamination. Personalised behaviour change interventions can aid in encouraging members of the public to engage with health services, as reported in a trial that assessed the effectiveness of a targeted GP postal letter to increase patient consultation rates for possible cancer symptoms. While an increase in the number of overall consultations among 


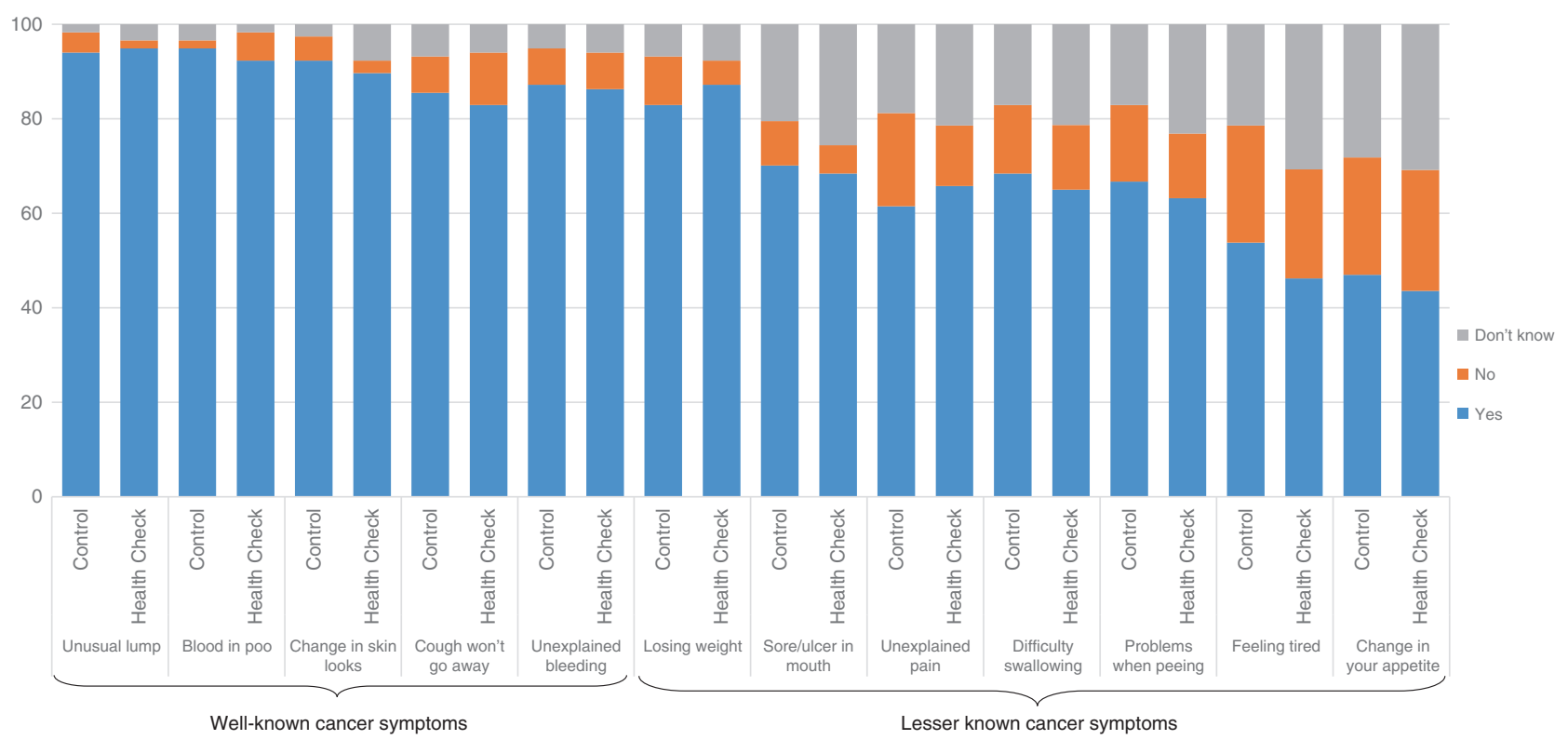

Fig. 2 Percentage of participant responses for "well know" and "lesser known" cancer symptoms. Percentage of responses in cancer symptoms.

Table 3. Regression analyses for sub-scores generated by factor analysis.

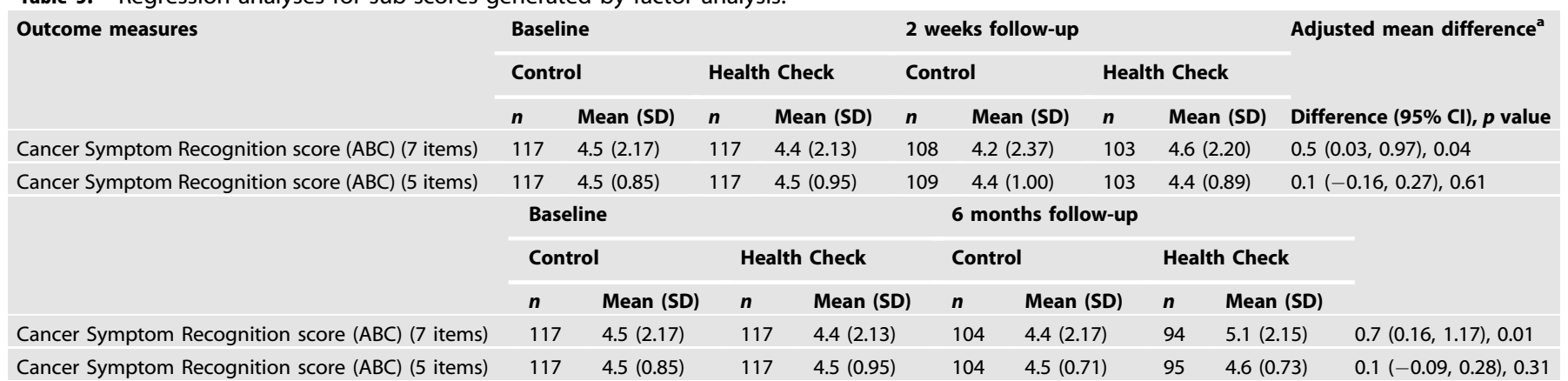

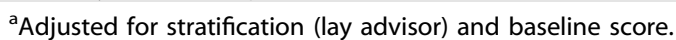

intervention arm participants was observed in this trial, the total number of patients with whom these took place did not increase [38]. Further targeted public health interventions are needed to engage those less likely to engage with cancer awareness initiatives and address the persistent socioeconomic disparity in cancer outcomes [39].

To our knowledge, the ABACus trial is the first to detail a complex behavioural cancer awareness intervention that successfully reached and engaged a highly deprived target population [27] and effected change in awareness and anticipated presentation for a range of common cancer symptoms. We used the validated Awareness and Beliefs about Cancer measure [32], adapted to low literacy levels and with additional measures of barriers derived from the Cancer Awareness Measure [40]. The finding of a baseline ceiling effect in participants' recognition of potential cancer symptoms is suggestive of measurement reactivity [41-43] and may partly reflect the effect of completing baseline measures immediately prior to intervention delivery. This is similar to Hubbard et al. [44], who found subtle increases in cancer awareness among adolescents enrolled in a trial of a brief school-based cancer awareness intervention. Following participation in a cancer awareness roadshow, Smith et al. [45] reported increased awareness of cancer risk factors and help-seeking behaviour but not increased symptom knowledge, which they attributed to ceiling effects and low intervention dose. However, we found that symptom knowledge was retained six months postintervention, suggesting that more intensive individually tailored and facilitated awareness interventions may be more effective for the target population over a longer period. Nevertheless, the development of guidance to support the minimisation of bias due to measurement reactions in studies of complex health interventions [46] is welcome and will improve future evaluation methods.

\section{Strengths and limitations}

A key strength is that the intervention was developed based on the Medical Research Council guidelines for developing and evaluating complex interventions [47] and principles of coproduction and was grounded in a theoretical understanding of the behavioural influences on cancer awareness and help-seeking in the target population $[26,48]$. The trial was sufficiently powered to detect changes in symptom awareness and the process evaluation indicates that the ability to tailor the intervention to individual needs and the personalised, facilitated nature of its delivery most likely explain its positive impact on awareness and anticipated presentation (HQ-S, YM, SG, SS, VS, JH, et al. unpublished). However, it is unknown whether and to what extent control arm participants were exposed to other local or national cancer awareness campaigns and how these may have impacted on the findings. 
Table 4. Mean per participant cost of healthcare resources $(£)$ used in the 6 months post-randomisation (6-month follow-up measurements); all available cases.

\begin{tabular}{|c|c|c|c|c|}
\hline Healthcare resource & Health Check group $(n=93)$ & Control group $(n=103)$ & Difference; $95 \% \mathrm{Cl}$ & $p$ value \\
\hline \multicolumn{5}{|l|}{ Primary care costs } \\
\hline Home visits (SD) & $0.00(0.00)$ & $0.63(6.34)$ & $-0.63 ;-1.92$ to 0.67 & 0.343 \\
\hline NHS Direct phone call (SD) & $0.00(0.00)$ & $0.00(0.00)$ & $\mathrm{n} / \mathrm{a}$ & $\mathrm{n} / \mathrm{a}$ \\
\hline $\begin{array}{l}\text { Total cost of primary care use per } \\
\text { participant (SD) }\end{array}$ & $10.14(40.65)$ & $10.84(29.83)$ & $-0.69 ;-10.67$ to 9.29 & 0.892 \\
\hline Emergency admissions (SD) & $22.22(214.24)$ & $5.01(50.89)$ & $17.20 ;-25.70$ to 60.11 & 0.430 \\
\hline Ambulance call-outs (SD) & $2.71(26.12)$ & $4.31(43.75)$ & $-1.60 ;-11.89$ to 8.69 & 0.759 \\
\hline Outpatient visits (SD) & $19.32(63.13)$ & $30.87(119.23)$ & $-11.55 ;-38.85$ to 15.75 & 0.405 \\
\hline Elective inpatient stays (SD) & $0.00(0.00)$ & $38.29(388.60)$ & $-38.29 ;-117.78$ to 41.20 & 0.343 \\
\hline Total secondary care cost per participant (SD) & $46.19(278.54)$ & $81.60(551.27)$ & $-35.40 ;-160.49$ to 89.68 & 0.577 \\
\hline Biopsy (SD) & $35.35(224.03)$ & $20.31(86.39)$ & $15.04 ;-31.94$ to 62.01 & 0.529 \\
\hline Smear test (SD) & $0.91(8.78)$ & $0.00(0.00)$ & $0.91 ;-0.90$ to 2.72 & 0.320 \\
\hline Total investigation cost per participant (SD) & $76.44(350.79)$ & $52.54(188.19)$ & $23.90 ;-54.37$ to 102.17 & 0.548 \\
\hline \multicolumn{5}{|l|}{ Other costs } \\
\hline Cancer advice (SD) & $1.71(7.51)$ & $1.15(6.13)$ & $0.56 ;-1.37$ to 2.48 & 0.568 \\
\hline Total cost of potential cancer investigation (SD) & $134.48(641.41)$ & $146.12(682.48)$ & $-11.64 ;-198.77$ to 175.50 & 0.903 \\
\hline \multicolumn{5}{|l|}{ Cancer treatment costs } \\
\hline Radiotherapy (SD) & $0.00(0.00)$ & $5.64(57.29)$ & $-5.64 ;-17.36$ to 6.07 & 0.343 \\
\hline Chemotherapy (SD) & $0.00(0.00)$ & $0.00(0.00)$ & $\mathrm{n} / \mathrm{a}$ & $\mathrm{n} / \mathrm{a}$ \\
\hline Surgery (SD) & $0.00(0.00)$ & $146.03(881.47)$ & $-146.03 ;-318.31$ to 26.24 & 0.096 \\
\hline
\end{tabular}

$\mathrm{Cl}$ confidence interval, $n$ sample size, $S D$ standard deviation, $n / a$ not applicable.

${ }^{\mathrm{a}}$ Result no longer statistically significant after Bonferroni-Holm correction for multiple comparisons.

We recognise the limitations of using self-report measures of knowledge, beliefs and behaviour and of measuring anticipated rather than actual symptom presentation behaviour, which may help to explain lack of observed effects. We acknowledge the low internal consistency of the adapted $A B C$ cancer belief measure. The $A B C$ measure was adapted to account for low literacy levels within our target population and we recognise that there is a need to further develop and test psychometrically robust measures of beliefs about cancer for use within this population group. Our sample also consisted of predominantly white British and native English speakers, further limiting the generalisability of the findings to a wider UK population including mixed ethnic groups and nonnative English speakers who may present with additional needs not addressed by our intervention. Future UK-wide implementation of the Health Check would need to consider any adaptations required to accommodate the needs of these populations.

\section{Implication for policy/practice and research}

The intervention has the potential to achieve public health benefits by encouraging cancer awareness and earlier presentation in socioeconomically deprived communities, with a lower cost than the median observed for public health interventions between 2011 and 2016 in the UK [49]. Our exploratory, modelbased cost-utility analysis showed that the Health Check has the potential to be cost-effective, or even cost-saving, over the longer term by potentially reducing later stage diagnosis and therefore improving longer-term outcomes [50, 51]. Further prospective, longer-term follow-up of larger cohorts using routine service data would provide more confidence in the effects of the Health Check on delays in symptom presentation, cancer stage at diagnosis and cancer outcomes, all of which affect cost-effectiveness.

Non-specific symptoms [52] such as persistent fatigue and unexplained weight loss are particularly difficult for people to recognise and are more likely to be dismissed than classic "wellknown" symptoms such as lumps and unexplained bleeding, because they can more easily be misattributed to the after effects of major illnesses, natural everyday occurrences such as minor illnesses, stress or the ageing process [9, 53, 54]. Individually tailored and demographically targeted community-based cancer awareness interventions such as the ABACus Health Check may complement the recently implemented Multidisciplinary/Rapid Diagnostic Centre referral pathways in England [55] and Wales [56] by increasing public awareness and prompting action in response to "lesser known", common cancer symptoms that are predictive of earlier stage disease [51]. Such initiatives may be important in responding to the impact of the coronavirus disease 2019 pandemic on symptomatic presentation in primary care $[57,58]$.

Our model of trained peer supporters delivering cancer awareness messages may present future implementation challenges within the UK health service provision system. However, the findings of improved cancer symptom recognition over a longer period, particularly for non-specific symptoms, are encouraging. There is potential for this model to be embedded and integrated across primary care, third-sector organisations and 
large employers and to be further adapted to investigate how this approach can be used across diverse communities (i.e. ethnic minorities, non-English speakers). However, this would require significant adaptations to accommodate cultural sensitivities and language barriers and further investigation to identify potential obstacles for wide-scale implementation and normalisation within a diverse UK context.

\section{Summary}

The ABACus Health Check is a viable low-cost intervention to increase cancer awareness and encourage earlier symptom presentation in socioeconomically deprived communities in the UK. Further implementation research is needed to collect longerterm presentation, diagnosis and outcome data and to evaluate whether the intervention can be scaled up and rolled out in the UK's socioeconomically deprived communities.

\section{DATA AVAILABILITY}

De-identified participant data will be made available to the scientific community upon request with an agreed/signed data sharing agreement.

\section{REFERENCES}

1. Rachet B, Ellis L, Maringe C, Chu T, Nur U, Quaresma M, et al. Socioeconomic inequalities in cancer survival in England after the NHS cancer plan. Br J Cancer. 2010;103:446-53.

2. Ellis $L$, Coleman MP, Rachet B. How many deaths would be avoidable if socioeconomic inequalities in cancer survival in England were eliminated? A national population-based study, 1996-2006. Eur J Cancer. 2012;48:270-8.

3. Lyratzopoulos G, Abel GA, Brown CH, Rous BA, Vernon SA, Roland M, et al. Sociodemographic inequalities in stage of cancer diagnosis: evidence from patients with female breast, lung, colon, rectal, prostate, renal, bladder, melanoma, ovarian and endometrial cancer. Ann Oncol. 2013;24:846-50.

4. Macleod U, Mitchell ED, Burgess C, Macdonald S, Ramirez AJ. Risk factors for delayed presentation and referral of symptomatic cancer: evidence for common cancers. Br J Cancer. 2009;101:S92-101.

5. McCutchan GM, Wood F, Edwards A, Richards R, Brain KE. Influences of cancer symptom knowledge, beliefs and barriers on cancer symptom presentation in relation to socioeconomic deprivation: a systematic review. BMC Cancer. 2015;15:1000.

6. Brown KF, Rumgay H, Dunlop C, Ryan M, Quartly F, Cox A, et al. The fraction of cancer attributable to modifiable risk factors in England, Wales, Scotland, Northern Ireland, and the United Kingdom in 2015. Br J Cancer. 2018;118:1130-41.

7. Richards MA. The size of the prize for earlier diagnosis of cancer in England. $\mathrm{Br} \mathrm{J}$ Cancer. 2009;101:S125-9.

8. Butler J, Foot C, Bomb M, Hiom S, Coleman M, Bryant $\mathrm{H}$, et al. The International Cancer Benchmarking Partnership: an international collaboration to inform cancer policy in Australia, Canada, Denmark, Norway, Sweden and the United Kingdom. Health Pol. 2013;112:148-55.

9. Quaife SL, Forbes LJL, Ramirez AJ, Brain KE, Donnelly C, Simon AE, et al. Recognition of cancer warning signs and anticipated delay in help-seeking in a population sample of adults in the UK. Br J Cancer. 2014;110:12-8.

10. Pedersen AF, Forbes $L$, Brain $K$, Hvidberg $L$, Wulff $C N$, Lagerlund $M$, et al. Negative cancer beliefs, recognition of cancer symptoms and anticipated time to helpseeking: an International Cancer Benchmarking Partnership (ICBP) study. BMC Cancer. 2018;18:1-10.

11. Robb K, Stubbings S, Ramirez A, Macleod U, Austoker J, Waller J, et al. Public awareness of cancer in Britain: a population-based survey of adults. $\mathrm{Br} J$ Cancer. 2009;101:S18-23.

12. Forbes LIL, Simon AE, Warburton F, Boniface D, Brain KE, Dessaix A, et al. Differences in cancer awareness and beliefs between Australia, Canada, Denmark, Norway, Sweden and the UK (the International Cancer Benchmarking Partnership): do they contribute to differences in cancer survival? $\mathrm{Br} J$ Cancer. 2013;108:292-300.

13. Robb KA, Simon AE, Miles A, Wardle J. Public perceptions of cancer: a qualitative study of the balance of positive and negative beliefs. BMJ Open. 2014;4:1-6.

14. Quaife SL, Winstanley K, Robb KA, Simon AE, Ramirez AJ, Forbes LL, et al. Socioeconomic inequalities in attitudes towards cancer: an International Cancer Benchmarking Partnership study. Eur J Cancer Prev. 2015;24:253-60.

15. Waller J, Robb K, Stubbings S, Ramirez A, Macleod U, Austoker J, et al. Awareness of cancer symptoms and anticipated help seeking among ethnic minority groups in England. Br J Cancer. 2009;101:S24-30.
16. Niksic M, Rachet B, Warburton FG, Wardle J, Ramirez AJ, Forbes LJL. Cancer symptom awareness and barriers to symptomatic presentation in England-are we clear on cancer? Br J Cancer. 2015;113:533-42.

17. McCutchan G, Wood F, Smits S, Edwards A, Brain K. Barriers to cancer symptom presentation among people from low socioeconomic groups: a qualitative study. BMC Public Health. 2016;16:1052.

18. Ironmonger L, Ohuma E, Ormiston-Smith N, Gildea C, Thomson CS, Peake MD. An evaluation of the impact of large-scale interventions to raise public awareness of a lung cancer symptom. Br J Cancer. 2015;112:207-16.

19. Power E, Wardle J. Change in public awareness of symptoms and perceived barriers to seeing a doctor following Be Clear on Cancer campaigns in England. $\mathrm{Br}$ J Cancer. 2015;112:S22-6.

20. McCutchan G, Smits S, Ironmonger L, Slyne C, Boughey A, Moffat J, et al. Evaluation of a national lung cancer symptom awareness campaign in Wales. $\mathrm{Br} J$ Cancer. 2020;122:491-7.

21. Moffat J, Bentley A, Ironmonger L, Boughey A, Radford G, Duffy S. The impact of national cancer awareness campaigns for bowel and lung cancer symptoms on sociodemographic inequalities in immediate key symptom awareness and GP attendances. Br J Cancer. 2015;112:S14-21.

22. Smith P, Smits S, Owen S, Wood F, Mccutchan G, Carter B, et al. Feasibility and acceptability of a cancer symptom awareness intervention for adults living in socioeconomically deprived communities. BMC Public Health. 2018;18:695.

23. Dahlgren G, Margaret W. Policies and strategies to promote social equity in health. Background document to WHO - strategy paper for Europe. Stockholm: Institute for Futures Studies; 1991.

24. Lyon D, Knowles J, Slater B, Kennedy R. Improving the early presentation of cancer symptoms in disadvantaged communities: putting local people in control. Br J Cancer. 2009;101:S49-54.

25. McCutchan G, Hiscock J, Hood K, Murchie P, Neal RD, Newton G, et al. Engaging high-risk groups in early lung cancer diagnosis: a qualitative study of symptom presentation and intervention preferences among the UK's most deprived communities. BMJ Open. 2019;9:1-12.

26. Smits S, McCutchan G, Wood F, Edwards A, Lewis I, Robling M, et al. Development of a behavior change intervention to encourage timely cancer symptom presentation among people living in deprived communities using the behavior change wheel. Ann Behav Med. 2016;52:474-88.

27. Kolovou V, Moriarty Y, Gilbert S, Quinn-Scoggins H, Townson J, Padgett L, et al. Recruitment and retention of participants from socioeconomically deprived communities: lessons from the Awareness and Beliefs About Cancer (ABACus3) Randomised Controlled Trial. BMC Med Res Methodol. 2020;20:272.

28. Moriarty Y, Townson J, Quinn-Scoggins H, Padgett L, Owen S, Smits S, et al. Improving cancer symptom awareness and help-seeking among adults living in socioeconomically deprived communities in the UK using a facilitated health check: a protocol for the Awareness and Beliefs about Cancer (ABACus) Randomised Control Trial. BMC Public Health. 2019;19:285.

29. UK Government. English Indicies of Deprivation 2015. UK Government. 2018. https://www.gov.uk/government/statistics/english-indices-of-deprivation-2015.

30. Welsh Government. Welsh Index of Multiple Deprivation (WIMD) 2014. Welsh Government. 2018. http://wimd.wales.gov.uk/.

31. Hoffmann TC, Glasziou PP, Boutron I, Milne R, Perera R, Moher D, et al. Better reporting of interventions: template for intervention description and replication (TIDieR) checklist and guide. BMJ. 2014;348:1-12.

32. Simon $A E$, Forbes LJL, Boniface D, Warburton $F$, Brain $K E$, Dessaix $A$, et al. An international measure of awareness and beliefs about cancer: development and testing of the ABC. BMJ Open. 2012;2:e001758.

33. Curtis LA, Burns A. Unit Costs of Health and Social Care 2019. Kent: Unit Costs of Health and Social Care; 2019. 176 p.

34. Beecham J, Knapp M. CSRI (Client Services Receipt Inventory) European version. 1997. http://www.dirum.org/assets/downloads/634462388066137028-CSRI.pdf.

35. Deparment of Health. NHS reference costs 2017 to 2018. 2018. https:// improvement.nhs.uk/resources/reference-costs/.

36. Eichstaedt KE, Kovatch K, Maroof DA. A less conservative method to adjust for familywise error rate in neuropsychological research: the Holm's sequential Bonferroni procedure. Neurorehabilitation. 2013;32:693-6.

37. Emery JD, Gray V, Walter FM, Cheetham S, Croager EJ, Slevin T, et al. The Improving Rural Cancer Outcomes Trial: a cluster-randomised controlled trial of a complex intervention to reduce time to diagnosis in rural cancer patients in Western Australia. Br J Cancer. 2017;117:1459-69.

38. Laake J-P, Vulkan D, Quaife S, Hamilton W, Martins T, Waller J, et al. Targeted encouragement of GP consultations for possible cancer symptoms: randomised controlled trial. Br J Gen Pract. 2021;71:e339-46.

39. Exarchakou A, Rachet B, Belot A, Maringe C, Coleman MP. Impact of national cancer policies on cancer survival trends and socioeconomic inequalities in England, 1996-2013: population based study. BMJ 2018;360:k764. 
40. Stubbings S, Robb K, Waller J, Ramirez A, Austoker J, Macleod U, et al. Development of a measurement tool to assess public awareness of cancer. $\mathrm{Br} \mathrm{J}$ Cancer. 2009;101:S13-7.

41. McCambridge J, Kypri K. Can simply answering research questions change behaviour? Systematic review and meta analyses of brief alcohol intervention trials. PLoS ONE. 2011;6:e23748.

42. Wood C, Conner M, Miles E, Sandberg T, Taylor N, Godin G, et al. The impact of asking intention or self-prediction questions on subsequent behavior: a metaanalysis. Pers Soc Psychol Rev. 2016;20:245-68.

43. Spangenberg ER, Kareklas I, Devezer B, Sprott DE. A meta-analytic synthesis of the question-behavior effect. J Consum Psychol. 2016;26:441-58.

44. Hubbard G, Stoddart I, Forbat L, Neal RD, O'Carroll RE, Haw S, et al. School-based brief psycho-educational intervention to raise adolescent cancer awareness and address barriers to medical help-seeking about cancer: a cluster randomised controlled trial. Psychooncology. 2016;771:760-71.

45. Smith SG, Osborne K, Tring S, George H, Power E. Evaluating the impact of a community-based cancer awareness roadshow on awareness, attitudes and behaviors. Prev Med. 2016;87:138-43.

46. Miles LM, Elbourne D, Farmer A, Gulliford M, Locock L, McCambridge J, et al. Bias due to MEasurement Reactions in Trials to improve health (MERIT): protocol for research to develop MRC guidance. Trials. 2018;19:1-8.

47. Craig P, Dieppee P, MacIntyre S, Michie S, Nazzareth I, Petticrew M. Developing and evaluating complex interventions: new guidance. 2019. https://mrc.ukri.org/ documents/pdf/complex-interventions-guidance/.

48. Michie S, Atkins L, West R. The behaviour change wheel: a guide to designing interventions. The behavior change wheel: book launch event. London: Silverback Publishing; 2014. p. 1-46.

49. Owen L, Pennington B, Fischer A, Jeong K. The cost-effectiveness of public health interventions examined by NICE from 2011 to 2016. J Public Health. 2018;40:557-66.

50. Neal RD, Tharmanathan P, France B, Din NU, Cotton S, Fallon-Ferguson J, et al. Is increased time to diagnosis and treatment in symptomatic cancer associated with poorer outcomes? Systematic review. Br J Cancer. 2015;112:S92-107.

51. Koo MM, Swann R, McPhail S, Abel GA, Elliss-Brookes L, Rubin GP, et al. Presenting symptoms of cancer and stage at diagnosis: evidence from a cross-sectional, population-based study. Lancet Oncol. 2020;21:73-9.

52. Pearson C, Poirier V, Fitzgerald K, Rubin G, Hamilton W. Cross-sectional study using primary care and cancer registration data to investigate patients with cancer presenting with non-specific symptoms. BMJ Open. 2020;10:e033008.

53. Whitaker KL, Scott SE, Winstanley K, Macleod U, Wardle J. Attributions of cancer "alarm" symptoms in a community sample. PLoS ONE. 2014;9:e114028.

54. Kummer S, Walter FM, Chilcot J, Emery J, Sutton S, Scott SE. Do cognitive heuristics underpin symptom appraisal for symptoms of cancer?: a secondary qualitative analysis across seven cancers. Psychooncology. 2019;28:1041-7.

55. Friedemann Smith C, Tompson A, Holtman GA, Bankhead C, Gleeson F, Lasserson $D$, et al. General practitioner referrals to one-stop clinics for symptoms that could be indicative of cancer: a systematic review of use and clinical outcomes. Fam Pract. 2019;36:255-61.

56. Sewell B, Jones M, Fitzsimmons D, Gray H, Lloyd-Bennett C, Beddow K, et al. Rapid cancer diagnosis for patients with vague symptoms: a cost-effectiveness study. $\mathrm{Br}$ J Gen Pract. 2020;70:E186-92.

57. Jones D, Neal RD, Duffy SRG, Scott SE, Whitaker KL, Brain K. Impact of the COVID19 pandemic on the symptomatic diagnosis of cancer: the view from primary care. Lancet Oncol. 2020;21:748-50.

58. Helsper CW, Campbell C, Emery J, Neal RD, Li L, Rubin G, et al. Cancer has not gone away: a primary care perspective to support a balanced approach for timely cancer diagnosis during COVID-19. Eur J Cancer Care. 2020;29:e13290.

\section{ACKNOWLEDGEMENTS}

The authors would like to acknowledge the Trial Steering Committee members (Chair: Professor Clare Wilkinson; Independent statistician: Dr Victoria Allgar Independent expert: Dr Katriina Whitaker; PPI: Dr Kathy Seddon) who provided overarching support and oversight of the trial conduct. We also thank Mrs Gemma Hamilton and Mrs Hasnae Khamlichi for their administrative support throughout the project and Ms Angela Farr and Dr Mari Jones for their work on the health economic evaluation.

\section{AUTHOR CONTRIBUTIONS}

All authors contributed to the design and/or delivery of the trial. YM was the trial manager and drafted the manuscript. KB was the chief investigator and maintained overall oversight and responsibility for the trial delivery. HQ-S, SO, LP, VK and SG supported the daily delivery of the trial by collecting and managing the data. LP, SO and VK were additionally responsible for intervention delivery. RT provided trial management input and contributed to process evaluation. JT provided senior trial management input and oversight of the day-to-day delivery of the trial. RP, ML, PD and BS provided day-to-day statistical and health economic analysis input. PB and JH provided lay input to the study design and implementation. SS provided behaviour change expertise and was key to designing the intervention and supported process evaluation design. $\mathrm{AE}, \mathrm{CM}$ and $\mathrm{RDN}$ provided clinical expertise and input and were key to designing the intervention as well as the study design. MM was key to the intervention design and provided day-to-day support with Welsh recruitment and implementation and supported the study design. MR provided expertise and input in trial delivery in vulnerable populations and supported the intervention development and study design. FW provided oversight of the qualitative analysis and supported the intervention development and study design. All authors have inputted to the manuscript draft and have read and approved the final version.

\section{FUNDING}

This work was supported by Yorkshire Cancer Research grant number C402. This research comes under the auspices of the Health and Care Research Wales funded by Primary and Emergency Care Research Centre (PRIME) [517195] and Wales Cancer Research Centre [517190]. The Centre for Trials Research (CTR) is funded through the Welsh Government by Health and Care Research Wales and Cancer Research UK.

\section{ETHICS APPROVAL AND CONSENT TO PARTICIPATE}

The London-Surrey NHS Research Ethics Committee (Ref: 17/LO/1507) approved this trial. UK-wide governance approval was granted from Health and Care Research Wales Permission Service. Written informed consent was taken from all participants in the trial at recruitment. This trial was conducted in accordance with Good Clinical Practice and the Declaration of Helsinki.

\section{CONSENT FOR PUBLICATION}

Not applicable.

\section{COMPETING INTERESTS}

The authors declare no competing interests.

\section{ADDITIONAL INFORMATION}

Supplementary information The online version contains supplementary material available at https://doi.org/10.1038/s41416-021-01524-5.

Correspondence and requests for materials should be addressed to Y.M.

Reprints and permission information is available at http://www.nature.com/ reprints

Publisher's note Springer Nature remains neutral with regard to jurisdictional claims in published maps and institutional affiliations.

Open Access This article is licensed under a Creative Commons Attribution 4.0 International License, which permits use, sharing, adaptation, distribution and reproduction in any medium or format, as long as you give appropriate credit to the original author(s) and the source, provide a link to the Creative Commons license, and indicate if changes were made. The images or other third party material in this article are included in the article's Creative Commons license, unless indicated otherwise in a credit line to the material. If material is not included in the article's Creative Commons license and your intended use is not permitted by statutory regulation or exceeds the permitted use, you will need to obtain permission directly from the copyright holder. To view a copy of this license, visit http://creativecommons. org/licenses/by/4.0/.

(c) The Author(s) 2021 


\section{ABACUS STUDY TEAM}

Yvonne Moriarty (D) ${ }^{1 凶}$, Mandy Lau ${ }^{1}$, Bernadette Sewell $\mathbb{D}^{2}{ }^{2}$, Rob Trubey ${ }^{1}$, Harriet Quinn-Scoggins ${ }^{3}$, Sioned Owen ${ }^{4}$, Louise Padgett ${ }^{5}$, Vasiliki Kolovou ${ }^{6}$, Julie Hepburn ${ }^{7}$, Peter Buckle ${ }^{8}$, Rebecca Playle ${ }^{1}$, Julia Townson ${ }^{1}$, Michael Robling ${ }^{1}$, Stephanie Gilbert ${ }^{1}$,

Polyxeni Dimitropoulou', Adrian Edwards ${ }^{3}$, Caroline Mitchell ${ }^{9}$, Maura Matthews ${ }^{4}$, Stephanie Smits ${ }^{3}$, Fiona Wood ${ }^{3}$, Richard D. Neal ${ }^{10}$, Kate Brain ${ }^{3}$, Mari Jones ${ }^{2}$ and Angela Farr ${ }^{2}$ 